\section{CASES ILLUSTRATIVE OF THE TREATMENT OF SOME VARIETIES OF CHRONIC RHEUMATISM.}

By C. HANDField JoNes, M.D., Senior Assistant Physician to St. Mary's Hospital.

The following cases of diseased action depending upon rheumatism seem of sufficient interest to be worth recording, if only as memoranda of well marked instances of disease, and of the action of remedies. The brief way in which they are reported was unaroidable, as they all occurred in hospital out-patients, and time was of course wanting to make detailed inquiries.

Case r. Jane F., aged 6, residing at Kensal Green, was admitted on Feb. 9th. She had a kind of fit, her mother stated, six wceks previously; but she did not lose her consciousness. At present, she was stupefied several times in the course of the day. She had pain in different parts of the head, which was not increased at night. The tongue was clean; the urine clear. She was living on the bank of anal, in a damp place. The following medicine was ordered:

\section{B Potassii iodidi 3 ss. Liquoris potasse 3 iss. Infusi calumbæ $\zeta^{i j}$. M. Sumat $३$ ss. ter die.}

Feb. 16th. She was decidedly better this week than last; but made a groaning dismal noise in her sleep, much more some nights than others. The medicines were continued.

Feb. 23rd. She was not free from fits, but had them certainly less often. Her mother said that when she was affected, she could compare her " to nothing so much as to a tipsy man in his foolish talk". The bowels were properly open; the pulse weak. The head was tender; she could not bear to have it touched. A blister was ordered to be applied to the neck.

B Ferri carbonatis gr. x. ter die.

March 1st. She had had no fit since the blister; but had one sharm attack on the night on which it was applied.

March 8th. She had no more fits, but rambled and talked during the night. The bowels were confined.

B Syrupi ferri iodidi $3 \mathrm{ij}$. Aquæ そुiss. M.

Sumat $\xi$ ss. ter die.

R Hydrargyri c. cretâ gr. ijj. Pulveris jalapæ gr. $v$.

Fiat pulvis alternis noctibus sumendus ad tres vices.

March 15th. She was improving; and did not talk so much during the night. The medicine was continued.

March 22nd. She had now quite lost all her former symptoms, and rested better at night.

April 5th. She was quite recovered, and gone to school.

REMARKs. That the pain in the head, and the cerebral disturbance, in this case, were occasioned by the action of the rheumatic poison seems pretty certain, from the nature of the pain, the tenderness of the scalp, the general progress of the disorder, the damp nature of the residence, and from the juvantia. The influence of local treatment was shewn in the good effects of a blister. Disturbance of the cerebral functions is by no means common, as the result of chronic rheumatism. Neither Dr. Copland nor Dr. Fuller makes mention of it. Had this affection continued longer, the chronic inflammatory action would, it is very probable, have produced hypertrophic thickening of the cranial bones, and a roughened state of their internal surface; and then the disorder would have become well nigh incurable. A female has been more than once under my care, in whom repeated rheumatic attacks, of the same chronic character, seem to have been the cause of imperfect speech and giddiness, with impairment of voluntary and mental power, from which she can obtain no relief.

Case II. P., female, aged $1 \frac{1}{\text { year, came under my care }}$ on May 10th. Her mother described her as a backward child. She had no teoth, and was frequently ailing. The tongue was not costed; the bowels rere in good order. The anterior fontanelle was depressed. The skin was in the marning cool. The child was very fererish and restless at night, becoming worse about 4 P.K.; constantly crying and moaning, very fractious and restless, rolling her head about. The feet were always swollen at night. The head, at the time of examination, was not hot. She had been ill fire days. She lived in a healthy place.

$$
\begin{aligned}
& \text { Be Potassii iodidi gr. ix. } \\
& \text { Liquoris potassa } 3 \mathrm{ss.} \\
& \text { Viri ipecacuan. } 3 \text { ss. } \\
& \text { Aque anethi } 3 \text { ix. } \mathrm{M} \text {. } \\
& \text { Sumat } 3 \mathrm{j} \text {. ter die. }
\end{aligned}
$$

May 15th. She had had two good nights; complained much less of the head, and was evidently much better; but had no appetite. The mixture was continued; and a toaspoonful of cod-liver oil was given three times a day.

June 30th. The mother called on me for another purpose, and told me on inquiry that the child had quite rocovered from her former symptoms, and had thriven much better.

REMarks. There was a good deal of apparent resem. beMAREs. There was a good deal of appare it might easily have been taken for a case of meningitis. Howerer, the depressed state of the fontanelle, the nocturnal exacer. bation, the swelling of the feet at night, and the absence of fever and of gastric disturbance, made it probable that the distress of the head was owing to a different cause. The beneficial influence of antirheumatic treatment was very apparent.

CASE III. W. W., aged 28, a cabman, was admitted on March 8th. He had had severe pain at the back of the head during two months. It was felt mostly at night, and had probably been brought on by damp. There was no disturbance of functions.

R Potassii iodidi gr. iv. Sodxe carbonatis gr. v. Decocti cinchon. ऊiss. M.

Fiat haustus ter die sumendus.

B Liniment. opii, Liniment. terebinth., $\overline{\mathbf{a}} \mathbf{a} \mathbf{\jmath j}$. M.

Fiat linimentum nuchæ applicandum.

March 15th. He was better.

R Potassii iodidi gr. vij. Sode carbonatis gr. v. Tincturæ cinchonæ $3 \mathrm{j}$. Decocti cinchonæ $3 \mathrm{j}$.

Fiat haustus ter die sumendus.

March 22nd. He was much better.

April 5th. Ile had quite recovered; but seemed to want a tonic. He was discharged with directions to continue the same mixture, without the iodide of potassium, for a few days.

REMarks. This was a typical case of rheumatic neuralgia cured by iodide of potassium. The man continued his occupation of cab driving all the time.

CASE IV. E. P., aged 32, wife of an omnibus conductor, was admitted 0ct. 9th. She was suffering from frontal headache, which was increased by the recumbent position. The head was tender to the touch. She often had pain in the ancles. Her sleep was broken. The bowels were costive; the tongue was slightly coated; the urine scalded, and was high coloured. She felt very weak.

B Potassii iodidi gr. iij.

Potassæe bicarbon. Oj.

Decocti aloes comp.

Infusi calumbæ, $\boldsymbol{\alpha} \overline{\mathbf{a}} \xi$ ss. M.

Fiat haustus ter die sumendus.

Oct. 20th. She was better. The legs were free from pain. The urine was clear, and did not scald. The draught was continued, with the addition of five minims of tincture of cannabis Indica.

Nov. 10th. She went into the country soon after the last report, and returned with the same symptoms. She was ordered to resume the medicine. 
Nor. 17th. She complained of itching all over, and some pin at the top of the hend. The other pain was less. The draught was continued, the tincture of Indian hemp being omitted.

Dec. 1st. The itching continued in some degree. She was directed to take a mixture of quinine with sulphate of iron three times a day; and four grains of compound aloetic pill at night.

Dec. 15th. She was stronger, but still felt rheumatic pains occasionally.

Dec. 29th. She was going on rery well, and felt " quite a different person". She was ordered to continue the medicine for a week.

Rexarks. The rheumatic symptoms in this case were very marked, amounting at first almost to subacuteness. After being relieved by the employment of iodide of potassium and alkalis, they persisted for some time in a less degree, and were finally removed by the tonic action of quinine and iron. It seems questionable whether the itching was a rheumatic affection or not; it might be regarded as an hyperæesthesia : but no mention is made by Romberg of any such state resulting from the presence of the rheumatic poison in the blood. It is very conceivable that the materies morbi of rheumatism circulating in the capillaries might cause some irritation of the nerves in the papillæ, and so give rise to itching, much in the same way as occurs in jaundice.

Case v. S. M., aged 33, a labourer, was admitted Feb. 16th. He had some short time ago an accident, which caused concussion of the brain; he was brought to the hospital, and, after remaining there several days, he was discharged. Very soon after this, he applied as an out-patient, complaining of severe pain at the left side of the head, extending up all over it. The pain was not constant; it was sometimes more severe at night, and sometimes by day. The patient was a stoutly built man, of rather sanguine aspect.

R Potassii iodidi gr. iv.

Liqnoris potassa $\mathrm{m}$.

Decocti cinchonæ ३iss. M.

Fiat haustus ter die sumendus.

Feb. 23rd. He did not feel nearly so much pain as the preceding week. The medicine was continued.

March lst. He had much pain at the back of the head on the left side, but slept well.

Sumat ferri carbonatis $9 \mathrm{j}$. ter dic.

Opiate liniments were ordered to be applied.

March 8th. He was much better, but still had some remains of the occipital pains. The draught prescribed on February 16 was resumed.

March 15th. He was not so well. A blister was applied to the back of the neck; and the carbonate of iron was continued.

March 18th. He had less pain since the blister, but was not free from it.

P. Potassii iodidi gr. x.

Sodæ sesquicarbonat. gr. $\mathbf{v}$.

Misturæ camphoræ $\xi_{j}$. M.

Fiat haustus ter dic sumendus.

March 22nd. He was much better. The medicine was continued.

March 29th. Colchicum was substituted by a friend, who saw him in my absence.

April 5th. The pain had returned, and had been much worse last week, principally on the left side.

Be Potassii iodidi gr.v.

Sodæ sesquicarbonat. gr. v.

Decocti cinchonæ Zj. . M.

Fiat haustus ter die sumendus.

A blister was applied behind the ear.

April 10th. The pain increased during the first three days of the week, but was subsequently less. Five grains of iodide of potassium and a drachm of tincture of cinchona were added to the draught.
April 16th. The pain was remitting, but on the whole less severe. The pulse was very weak.

April 17th. The patient was ordered to take mixture of quinine with sulphate of iron three times a day; and half a grain of extract of belladonna three times a day.

April 22nd. He felt a great deal better, and had rery little pain.

April 26th. He was in about the same state. The appetite was good; but his strength did not increase. The pulse was of rather better force. The decayed stump of the last molar tooth was found to be exciting irritation in the upper alveolar arch. The medicines were continued : Fand equal parts of creasote and laudanum were ordered to be applied to the decayed tooth.

May 5th. The head was almost entirely free from pain; but he had a little on the right side.

May 10th. He had no return of the pain in the head; and was discharged cured.

REMARKs. The previous concussion of the brain might have excited suspicion how far the pain of the head was merely neuralgic. Relief was soon obtained by the employment of iodide of potassium; but afterwards, even in much larger doses, it ceased to produce a good effect. Colchicum was not beneficial; and belladonna did not seem to be of any particular use. The quinine and iron were the most effective remedies. The man continued, I believe, at his work as a labourer; but the debility which he experienced was very manifest. This seems to be a common feature in these neuralgiæ.

CA8E VI. W. B., aged 39, a compositor, was admitted September 16th. He had very recently been in the hospital, suffering from weakness and painful aching of the limbs: he went out nearly, but not quite recovered, and soon relapsed. He stated that he had formerly had gout. His right arm was now much affected. Iodide of potassium with bark was given thrice daily, and camphor with benbane at night. He was ordered to rub an opiate liniment on the part.

Sep. 20th. He said that he was improved, and that he slept better. The pains in the limbs were diminishing, but were brought on by exercise.

Sep. 27 th. He was improving "nicely".

October 4th. He had been much better during the last week, the pains gradually decreasing.

October 21st. He had pain in both loins, and some weakness in the elbows and arms. The urine was not clear, and high coloured.

B Potassii iodidi gr. v.

Potasse bicarbonatis $\ni i$.

Decocti cinchonæ そiss. M.

Fiat haustus ter die sumendus.

B Extracti aloes aquosi,

Extracti nucis vomice, āá gr. i.

Fiat pilula bis die sumenda.

October 25th. The pain was much more severe in the arms and shoulder. The tongue was clear; the urine clear: his bowels were open.

Re Syrupi ferri iodidi $\mathbf{3}$.j.

Potassii iodidi gr. viij.

Decocti cinchonæ $\xi_{j}$. M.

Fiat haustus ter die sumendus.

October 25th. He was wonderfully better since taking the last medicine.

November 1st. He was improving nuch, but had no flannel, and was half starved. The medicine was continued.

November 4th. He had no pains in the arms, and felt very well, but had an abscess forming near the anus. On account of this, he was again admitted as an in-patient. It was opened, and discharged purulent matter for some time. He left the hospital November 23rd, and did not present himself as an out-patient.

REM AREs. The rheumatic nature of the affection in this patient was not at first apparent; it was not regarded as such during his first stay in the hospital. The effect of remedies, the occasional shifting of the pains to other parts, and 
the condition of the urine on the 21st, when a relapse took place, seem to show pretty certainly that it had its origin in this most common cause. It is also very probable that the ahscess in the nates was connected with the same constitutional state; that it became, in fact, a focus of eliminative action. I had at one time a case under my care in which the symptoms presented at the outset the appearanee of rheumatic fever, but quictly changed to a typhoid state; while collections of ratter continued to form for a long time in various parts of the limbs. The cause of this unusual change can only be sought for in some peculiar condition of the vital powers, in consequence of which a disposition to generate pus took place of that which ordinarily produces lactic acid, the received nuateries morti of rheumatism.

Case vir. M. A. S., aged 42 , married, had rheumatic pains all over her. They were most severe in the hands. Her urine was generally high coloured, and deposited lithic acid. The tongue was smooth, clear, and moist. Her digestion was pretty good.

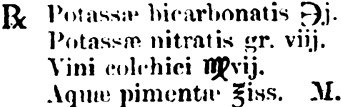

Fiat haustus ter die sumenilus.

B Pilule hydrargyri enm coloegnth. gr. $v$.

Fiat pilula omni nocte sumenda.

July 4th. She hat had severe diarrhœa, which had not yet subsided. The bowels were open eight or nine times on the preceding day. The tongue was clean.

B A.idi sulphurici liluti 3 ss.

linctura on:ii miv.

Aqua j̈j. II.

Fiat haustus ttis horis sumendus.

July 7 th. The howels were quiet. The rheumatic puins were troublesome, "all in the flesh". The urine did not deposit red sand.

Bx Infusi gentiane comp. 亏.j. Anmoniae muriatis gr. $\mathrm{xv}, \mathrm{M}$.

Fiat haustus ter die sumendus.

July 25th. She felt quite well, and wished to be discharged, saying that she was a good deal hetter for the medicine.

REMArks. The rheumatism in this case was chiefly muscular; and the good effect of muriate of ammonia on it was very marked.

CaSE vili. S. F., nged 41, was admitted on July 14th. She had dreadful pain between the shoulders on moving. The urine presented nothing remarkable. IIer digestion was not good. She had catarrh a month previously, to which she attributed her complaint.

R Potassii ionlidi gr. iij.

Potassar licarbonatis gr. $x$.

Infusi gentiana comp. そ̌j. M.

Fiat haustus ter die sumendus.

B Camphorir gr. i.

Fxtracti liya: cyami gr. iiss. Ir

Fiat pilula ter die illmenila.

July 18th. She stated that the medicine caused swelling of the eyes (eyelids); but there was none seen.

B P'otassid iodidi gr. iss.

Sodir sespuicarbonat. gr. v.

Acidi hydrocyauici dilnti mev.

Infusi gentians comp. 亏ुj. M.

Fiat hanstus ter die sumendus.

The pills were continued.

July 21 st. The shoulders were better. The medicines were continued.

July 28th. The pains "went and returned again".

R Ammoniar muriatis gr. $x v$.

Decocti cinchons zj. M.

Fiat haustus ter die sumendus.

August 4th. She was much better.

August 25th. She was discharged, well.

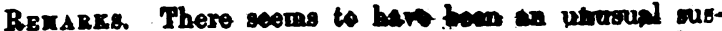
ceptibility in this case to the infuewce of iodine, as a doos of three grains of iodide of potassium cauped irritant effects. The diminished dose (gr. iss.) was borne well. In this case, also, muriate of ammonis was of much use.

1, Southwick Place, Hyde Park, London, Sep. 1sth, $185 s$.

\section{BIBITOGRAPHICAT ROTICES.}

Practical Observations on Aural Surgery, and the Nature AND Treatyent of Drgeages of the Ear. By Williax R. Wilde. pp. 506. London : 1853.

WE have had much pleasure, and not a litkle profit, from the perusal of this very excellent work, which we have placed on our shelves beside other standard treatises, the works of good, clear-headed, observing men-not "spe cialists", but sound scientific practitioners, entitled to the confidence of the profession, and wholly deroid of quackery or puffing.

From the situation of the organ of hearing, and the comparative difficulty of inrestigating the morbid appearances it may present, it has been till lately one of our medical opprobria, and has fallen under the dominion of quacks, lay and medical, the latter of whom Mr. WiLDE justly castigates in the "History of Aural Surgery" which forms the introduction to this hook. He divides the history into three epochs, the first marked by the introduction of the speculum (Fabricius); the second, by the application of Eustachian catheterism (Cleland); and the third, by the operation of perforating the membrana tympani, in certain cases of deufness (Sir A. Cooper).

The second chapter of the work contains the means of Diagnosis of Diseases of the Ear, and the Mode of Applying Instruments. We have for several years been ourselves in the halit of employing the simple and convenient speculum recommended by Mr. Wilde; it is a polished conical silver tube, of such a size as to fit the meatus, and infinitely to be preferred to the complicated instruments which have been so much vaunted. It \& should be made as light as possible, highly polished both inside and out, with a stout rim or brim round the larger margin, and the smaller aperture well rounded off, so as not to irritate the ear." The patient. is to be placed opposite a window into which the sun is shining; and the membrana tympani can now be easily seen and examined. Lamp-light is to be discarded.

The stethoscope, applied over the ear, is useful in enabling the surgeon to appreciate the varieties of sound produced on driving air into the t.ympanum, either by an expiratory effort on the part of the patient, or through the Eustachian catheter. This last named instrument, Mr. Wilde con. siders, will be found much less frequently necessary than many fancy; and he raises his voice against introducing probes into the drum of the ear, and among its small bones. The Eustachian catheter which he recommends is much wider than those commonly seen, and is always to be introduced through the nostril; but he repeats that, when the patient is able to inflate the membrana tympani himself, or when the carity is inttamed, catheterism of the tube should never be employed.

We have in this chapter some observations on tinnitus, and its various characters. These Mr. Wilde cannot connect with any special lesions of the apparatus of hearing; in fact, he thinks that the description which patients give of the noises in their ears depends mostly upon fancy; servants invariably stating that they suffer from "the ringing of bells"; while, in his eountry, old women usually sum up their complaints by saying that "all the kettles in Ireland are boiling in their ears". Our author states that the tincture of arnica has proved useful in some cases of tinnitus.

In leeching the ear, the animals should be made to bite close to the orifice, or just behind or in front of the babe of 